\title{
Setting an agenda for English for Academic and Professional Purposes in Spain
}

\author{
Keith Stuart and Ana Botella \\ Polytechnic University of Valencia \\ kstuart@idm.upv.es
}

\begin{abstract}
This paper outlines the practical implications of the use of the term English for Academic and Professional Purposes (EAPP), a position originally taken by Alcaraz (2000). The article proposes an agenda for EAPP within tertiary level education in Spain. Firstly, we propose a methodological and theoretical linguistic framework for our EAPP classes in our engineering and business degrees, which takes the form of Personalized Learning and Continuous Evaluation and links our ideas about the nature of language issues in EAPP with a rigorous theoretical framework based on Hallidayan Systemic Linguistics. Secondly, we describe a methodology for Academic English based on corpus linguistic techniques, which involves the building and processing of a corpus rapidly so as to extract lexico-grammatical information that has direct application in the classroom. Thirdly, we suggest that English for Professional Purposes consists of interpersonal activities such as being able to negotiate effectively; conduct interviews and surveys; listen and take notes during meetings and presentations; communicate effectively on the telephone as well as with video conferencing technology; carry out oral presentations etc. Finally, we conclude this paper outlining the specific skills that would be needed by a teacher of EAPP.
\end{abstract}

\section{Introduction}

This paper outlines what the authors consider to be the practical implications of the use of the term English for Academic and Professional Purposes (EAPP), a position originally taken by Alcaraz (2000). In the Anglo-Saxon tradition, this is covered by the use of terms such as EAP 
(English for Academic Purposes), ESP (English for Specific Purposes) and BE (Business English). However, it seems to us that the term English for Academic and Professional Purposes (EAPP) describes more accurately the teaching of English as a Second Language on University degrees across the globe and, more particularly, in Spain. One might question whether it is so important to call the field EAPP rather than EAP. It may also be argued that to a certain extent the line between professional and academic purposes is sometimes difficult to draw. The entire field of English for Law is probably a case in point, since students and researchers as well as practitioners in law will find it useful to embark on an in-depth study of this professional register, which necessarily covers both aspects. The line is probably most blurred in Business English and the balance dips on the side of English for Professional Purposes. But, it is not only in Business Management degrees that the balance tips strongly towards English for Professional Purposes, it is also the case in Engineering degrees where students need, for example, to acquire the professional skill of making oral presentations of their work. So there is clearly a need for both English for Academic Purposes and English For Professional Purposes and more so now that new degrees have been introduced in the European Union with the explicit aim of putting professional people onto the labour market in three or four years who then may specialize in their academic field by taking a Master. European undergraduate degrees are now focussing on the employability of their undergraduates and the acquisition of competences rather than on more exclusively academic skills. This does not detract from academic knowledge but the emphasis has shifted from a less bookish approach to a more interpersonal, interactive and communicative kind of learning where group work, project work and other highly collaborative activities are given greater priority.

The paper sets out an agenda for EAPP within tertiary education in Spain so does not pretend its applicability in all social contexts (other European or non-European countries) except the one that is most familiar to the authors. We would also like to show what practical implications this may have in the classroom; the practical implications of teaching Academic English and Professional English. For the academic part, we take as a case study the language of nanotechnology and discuss how corpus linguistic techniques make lexico-grammatical patterns in the language of nanotechnology rapidly available to the teacher, along with the ability to produce authentic corpus-driven teaching materials. In other words, our approach to Academic English is through corpus linguistic techniques and the analysis of texts to glean information about naturally occurring uses of language. For the professional part, we reflect on what that might mean in the classroom, the kind of skills that need to be taught and the materials that a teacher needs to use. To be competent professionals, our students need interpersonal skills; the acquisition of social and communicative abilities such as presenting information in public, negotiating, selling, persuading, explaining, etc. However, as we are dealing with a particular social context (the Spanish University system), we also describe an overarching methodological framework for dealing with students learning English on our university degrees (Engineering and Business degrees). This methodological framework takes the form of Personalized Learning and Continuous Evaluation and is currently under development within the ALVA Project (Aprendizaje de Lenguas con Valor Añadido - Value Added Language Learning). The paper begins describing this methodological framework and 
then goes on to detail the practical implications of teaching Academic English and Professional English along with some example classroom activities.

\section{Methodological and Theoretical Linguistic Framework for EAPP}

As already stated, we are developing a methodological framework for our EAPP classes in our engineering and business degrees, which has taken the form of Personalized Learning and Continuous Evaluation. Some of the principle elements of our methodological perspective are described below.

We want to enhance language learner progression (value added language learning) by offering a personalised learning environment. Our project will investigate and identify solutions to the issues and challenges that arise in providing a personalised learning experience which meets the needs of individual learners in a range of settings in their learning journey throughout their university life. The project will explore these issues through the implementation of e-portfolios, blogs and other social software to support widening participation and developing skills essential to successful language learning. More particularly, our methodological focus means that we will be implementing individual learning plans. Our methodological framework and the one we propose for EAPP is fundamentally concerned with:

- $\quad$ putting the language learner at the centre of the system;

- $\quad$ making the system work for the language learner;

- $\quad$ having high expectations of every language learner;

- $\quad$ shaping teaching around the way students want to learn;

- $\quad$ promoting language learning beyond the classroom;

- $\quad$ putting ICTs at the service of language learners;

- make learning interactive and collaborative through the use of social software;

- $\quad$ focusing on developing language learning skills and strategies (metacognition);

- providing clear language learning pathways through the education system and retaining their interest in languages throughout their degree course;

- planning for a combination of independent and collaborative language learning;

- $\quad$ using the learning needs of our students to guide our decision making;

- allowing for individual interpretations of the goals, value and best way of language learning.

Choice is also paramount, personalisation promises more choice about what students learn and how they learn the language. At the same time, the role of the teacher has to become one of advisor and facilitator as well as fulfilling the more traditional role of being a knowledge source.

There are three fundamental components of Personalized Learning and Continuous Evaluation, which need to be embedded in the whole language learning process and practice to enhance language learning outcomes. 
- ASSESSMENT FOR LEARNING: teachers and learners identify areas of strength and learning needs, and set targets to drive up individual attainment.

- EFFECTIVE TEACHING AND LEARNING STRATEGIES: developing a repertoire of skills to actively engage and stretch learners, building on their prior knowledge and experience, and incorporating individual and group activity. ICT has a central role to play, allowing students to work at their optimum pace, as well as providing greater opportunities for collaboration.

- ORGANISATION AND CHOICE: personal and flexible learning pathways through the education system and an organisational model which empowers students, supporting high quality language teaching and language learning.

Let us examine in greater detail what is meant by assessment for learning (Manitoba Education, Citizenship, and Youth Report, 2006: 29). The washback effect is well-known in language learning. Tests are assumed to be powerful determiners of what happens in classrooms and it is commonly claimed that tests affect teaching and learning activities both directly and indirectly. The various influences of tests are often referred to as washback (or backwash). This potentially positive or negative impact of test design on the form and content of English language courses, whether they may be for specific or general purposes, is a phenomenon known to most language teachers. Many students are first and foremostly interested in how they are going to be evaluated. In other words, students want to know the type of test/exam they are going to get; the way in which the test is delivered and marked; and, most importantly, the language content of the test. This can affect the way language training is designed, the language skills which are targeted and, ultimately, the quality of the language training that takes place. For good or for worse, the washback effect exists (Brown, 1999; Alderson \& Wall, 1993). In other words, assessment impacts on language learning. How can we make assessment work for language learning?

The most important part of assessment is the interpretation and use of the information that is gleaned from it. In assessment for learning, teachers use assessment as an investigative tool to find out as much as they can about what their students know and can do, and what confusions, preconceptions, or gaps they might have. The wide variety of information that teachers collect about their students' learning processes provides the basis for determining what they need to do next to move student learning forward. Teachers also use assessment for learning to enhance students' motivation and commitment to learning. When teachers commit to learning as the focus of assessment, they change the classroom culture to one of student success.

What does this mean in practice? It means two things from our point of view: 1) a diagnostic assessment in the student's first year of their degree with follow-up (continuous evaluation) on their future progress; 2) high-quality record-keeping. 
Diagnostic Assessment

The diagnostic assessment we suggest consists of the following:

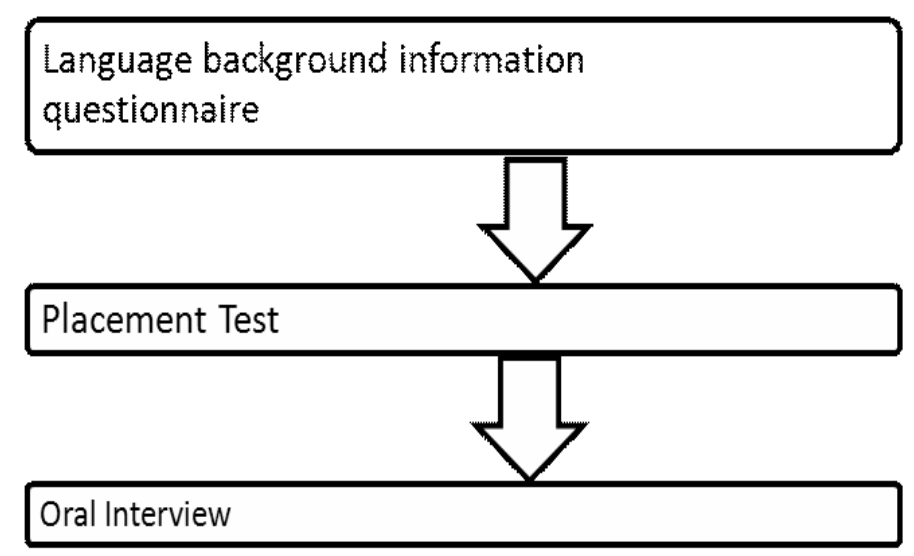

Figure 1. Assessment for Learning.

The first part of the diagnostic assessment is to gain information about general aspects of their language learning. The second part assesses their linguistic abilities (vocabulary, grammar, reading and writing). The third part is used to contrast their language skills as demonstrated in the second part with their oral production and reception skills while at the same time checking the validity of the placement test.

High-quality record-keeping is critical for ensuring quality in language classroom assessment. The records that teachers and students keep are the evidence that support the decisions that are made about students' learning. The records should include detailed and descriptive information about the nature of the expected learning as well as evidence of students' learning, and should be collected from a range of assessments. The record should represent a progress report whereby a student enters the system with certain language skills and leaves university with value added onto their language skills (value added language learning).

Although this is presented as a "framework for implementation" and it is difficult to argue with much of the sentiment underpinning personalised learning, it will be important to maintain a critical distance to it. A number of challenges and risks can be identified such as accentuating differences in attainment of language proficiency, because good language learners tend to be more conducive to "self-provisioning". Another identified area of potential difficulty is realism, whether it is over-ambitious with the kind of resources most teachers have available. Again here ICT can help by reducing workloads and automating many processes.

Undoubtedly, personalisation carries with it implications for workload, as well as teacher learning. However, perhaps more importantly, there now needs to be documentation that outlines with clarity the issues surrounding the concept of personalised language learning. Several common misconceptions, which are likely to induce wariness in teachers, are to be avoided. Personalised learning does not mean, for example, that students are left to their own 
devices to learn as individuals; collaborative and community learning is encouraged, although independent learning can complement this. Neither does it mean preparing individual lesson plans for different students, which is not realistic; although differentiation is likely to be set up through making available different resources to individual language learners. An awareness of multiple intelligences and learning styles is also important, so that teachers can provide a range of language learning experiences and opportunities to engage students emotionally and intellectually. Once you have students engaged in the language learning process half the battle has been won.

Before going on to detail the practical implications of teaching Academic English and Professional English, we would like to conclude this section by putting our ideas about the nature of EAPP into a more rigorous theoretical linguistic framework. To use a Hallidayan metaphor, we may say that the Academic part of EAPP is the ideational content whereas the Professional part is the interpersonal dimension.

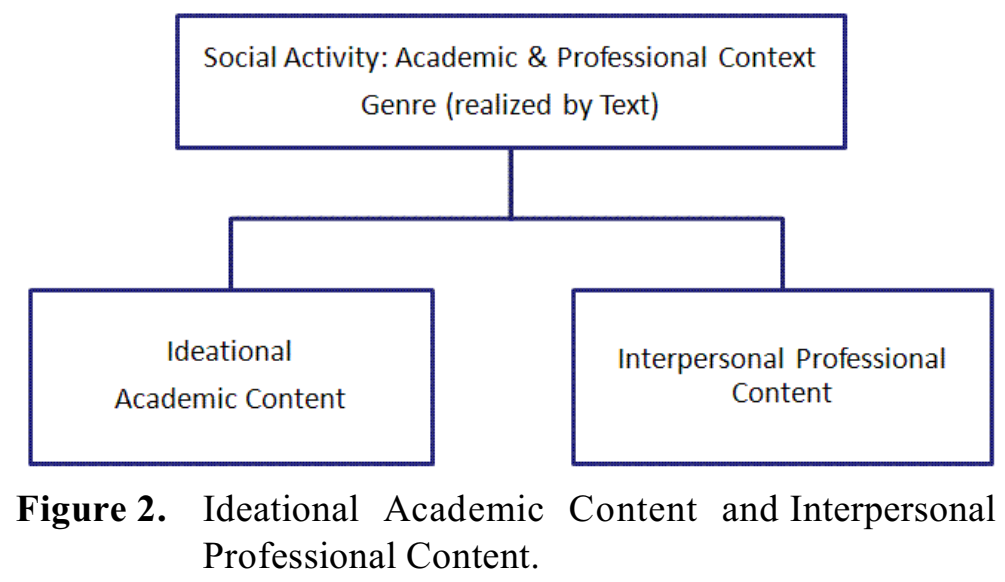

This can be broken down further by analysing the linguistic skills to be acquired in each of the two dimensions: the ideational dimension and interpersonal dimension. Typical ideational choices are noun phrases, nominal groups (participants); verbs (material, behavioural, mental, verbal, relational processes); prepositional phrases, adverbial adjuncts, and other resources for expressing circumstance (time, place, manner). Typical interpersonal choices are mood (statements, questions, demands); modality (modal verbs, and adverbs) and other resources for evaluative and attitudinal meaning. So, when we are teaching Academic English, we are concentrating on Ideational lexico-grammatical choices; whereas, when we are teaching Professional English, we are concentrating on Interpersonal lexico-grammatical choices.

\section{Academic English and Corpus Linguistics}

Corpora can be used to help address various linguistic research questions, including research into the language of science and technology. Sinclair (1991: 4) defined a corpus as "a collection of pieces of language, selected and ordered according to explicit linguistic criteria 
in order to be used as a sample of the language." For EAP and ESP, corpus linguistics has come to mean the use of corpora to gain quantitative data on phenomena that are otherwise hard to pin down, because they are dependent on the discourse conventions and the specific lexico-grammatical realisations of the academic genre in question.

There are linguistic issues which are dependent on genre, and that having a well-balanced representative specialist academic corpus can help reduce the risk of blindly making statements about the genre without having looked at the empirical data. Corpora of academic texts can offer lexico-grammatical patterns that show statistical regularities, which may be taken to be typical of that kind of discourse and may be useful linguistic data to be converted into teaching materials.

Why should one use a corpus as a teacher of Academic English? Firstly, corpora are a source of linguistic examples for teaching materials; and, secondly, corpora can help determine what should be taught by knowing how widespread a phenomenon is in the language. Similarly, teachers' (and text books') preconceptions are often wrong. Furthermore, corpora can act as a source of explanation to students about subtle differences in language, for example, differences between close synonyms, especially when the L1 doesn't make a similar distinction. Corpus evidence can be better than teachers' intuitions. Accurate information about usage can be obtained from corpus data. Corpora can answer questions such as how are sentence-initial conjunctions used. "However, moreover, furthermore, in addition etc." are sentence-initial conjunctions that students often have problems with but are essential for structuring academic discourse and are typically taught on academic writing courses as discourse signals and intersentential connectors.

In what follows, we take as a case study the language of nanotechnology and discuss how corpus linguistic techniques make lexico-grammatical patterns in the language of nanotechnology rapidly available to teachers, so they are able to produce authentic corpusdriven teaching materials.

Engineering students need to grasp the terminology and language of new technological developments, not only in their mother tongue but also in English. English is the language used to report on new scientific advances through research articles. Subject matter lecturers often recommend these articles as bibliography. Our mechanical engineering and material science students need to know about emerging fields such as nanotechnology. The field of nanotechnology is becoming ever more mainstream and spilling over into many other fields, so students from other degrees taught at our Institution such as Chemical and Electrical Engineering also need to familiarise themselves with the language of nanotechnology. The approach to EAP instruction based on corpus work is similar to that found in Gledhill (2000); Ward (2007); Martínez, Beck \& Panza (2009).

A corpus of academic articles constitutes a valuable tool as a repository of genre specific terminology (in our case, technical and sub-technical terms used in nanotechnology) and as a repository of lexico-grammatical patterns; in other words, key features of language use in domain specific settings. Our current research analyses 370 nanotechnology articles (from now on referred to as Nano-Corpus) using various software tools to be able to quickly and efficiently gather information about the structure of these texts, lexical clusters, collocations, and grammatical features. The total number of running words in the texts is $1,882,320$. 
Having described the methodology used for extracting and processing linguistic data, we then suggest how this data may be turned into language information in the form of teaching materials/activities for the classroom.

\subsection{Nano-Corpus Analysis}

To analyse the corpus, we followed the method proposed by Scott \& Tribble (2006) at its various stages. The software tool used for this was Wordsmith Tools (version 4.0). The main steps in the process can be outlined as follows:

\footnotetext{
1. Word List extraction

a. From Nano-Corpus as a whole

b. From each individual journal
}

2. Key Words extraction (reference corpus used: British National Corpus)

a. Nano-Corpus compared to BNC

3. Key key words extraction

a. Each individual journal compared to Nano-Corpus

4. Generation of collocates list
a. From Nano-Corpus as a whole
b. From each individual journal

5. Concordance lines generation
a. From Nano-Corpus as a whole
b. From each individual journal

6. Generation of word-clusters

a. From Nano-Corpus as a whole
b. From each individual journal

Table 1. Corpus analysis with Wordsmith Tools.

Data collected in this quantitative fashion reveal important facts about frequency of terms used in the discipline, the combinations of these terms both with functional words and with other content words. Likewise, word clusters provide lexico-grammatical details on recurrent patterns of academic discourse in general and the field of nanotechnology in particular.

The analysis obtains quantitative results which can be used together with resources available through the internet and will provide the ESP/EAP teacher, a non-expert in this specialised area, with sufficient competence and topic-related resources to design activities for the language classroom. In the following section, we will provide some ideas for the design of activities that could be implemented in our EAP classes.

\subsection{Example Materials}

A learning module could cover the areas described in the sections below. 


\section{a) Vocabulary used in EAP/Nanotechnology}

At this stage, simple exercises can be designed to create students' awareness of the use of technical and semi-technical terms in the field of Nanotechnology. This type of activity may include the use of already existing word lists of General English (such as a wordlist derived from the BNC, as in our case) to be used in parallel and for making comparisons between different lists (in other words, between general and specific English). The questions that could be addressed at this point are:

- Which terms are normally used with the same frequency in both lists?

- What similarities/differences are found in our Nano-Corpus word list?

- What grammatical categories do these words fall into?

Similarly, the activity could involve the use of General English lists organised by grammatical category (nouns, verbs, adjectives, etc.) and their comparison with the use of the different grammatical categories (nouns, verbs, adjectives, etc.) in our corpus. The teacher might wish to draw students' attention towards facts such as: the use of functional and grammatical items as being the most frequently used in a General English Corpus. In a General English corpus, content words tend to refer to "humans and what they have recently said, known and seen" (Scott \& Tribble, 2006:24) and are to be found lower down in a word list. By contrast, content terms with a higher semantic load are found nearer the top of the list in a specialist corpus ('surface', 'temperature', 'nanoparticles', 'nanotubes', 'carbon', etc.).

Furthermore, learning activities could be designed and developed with our key word lists, where comparison could be established between the different sub-corpora and the whole Nano-Corpus. At this point, more technical terms will provide the basis for further activities comprising the evaluation of the terminology used in the different journals, even distributing the lists depending on the area of specialization of the students/journal.

\section{b) Brainstorming the Topic}

Once we have established the scenario where our students are becoming aware of the differences between everyday language and the specialist terminology used by researchers for a specific technology, we are ready to carry out an interactive activity, involving student oral participation oriented towards eliciting previous knowledge on the topic which they have acquired in their specialist subjects (transdiciplinary learning). A preparatory activity (homework) would involve searching for definitions, images and finding out how different communities use this emerging technology for different purposes and the presentation of this information to the rest of the class. 


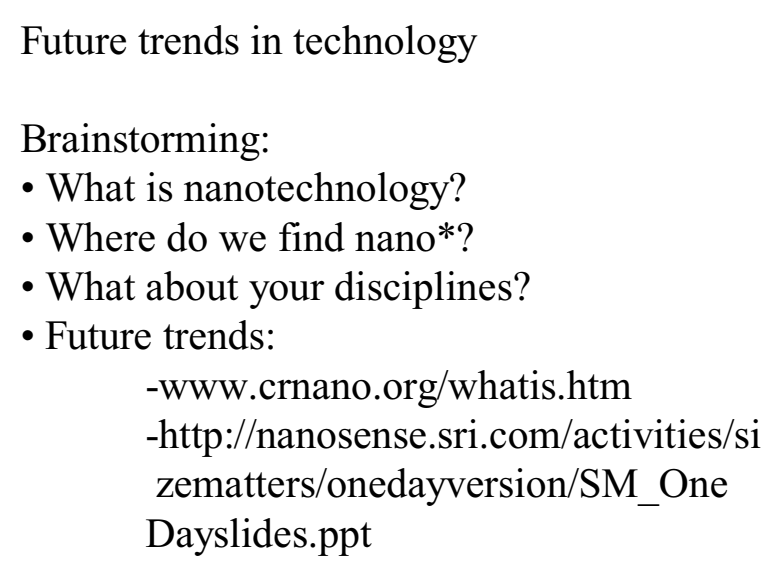

Figure 3. Brainstorming activity (screenshot).

\section{c) Word combinations: Collocates}

The next section in our module could include the use of our collocate list. One possible way of exploring these questions is by working with frequent semi-technical words that are found across the disciplinary fields of science and technology ('results', 'sample', 'value', etc). Interesting lexico-grammatical facts emerge from corpora such as the fact that the most frequent collocation found for results, 'the results obtained', is followed by different prepositions, depending on the noun group that follows the preposition. Similar lexicogrammatical patterns are found by analysing recurrent strings containing key semi-technical words ('of a/the X value of', 'for a/the value of', 'with the value/s of', etc.). Then we might focus on the collocates for a selected set of relevant key words in the specific domain, such as those with the prefix nano-, or multi- (both frequent in the corpus). The task would consist of searching for information relating concepts that form pairs of collocates. The students could even search for them directly in the corpus (laboratory activity).

\begin{tabular}{ll} 
nanochannels & fabricated \\
\hline nanocomposite & materials \\
\hline nanocomposite & properties \\
\hline nanocones & carbon \\
\hline nanocrystalline & materials \\
\hline nanocrystalline & alloys \\
\hline nanocrystalline & properties \\
\hline nanocrystalline & metals \\
\hline nanocrystals & semiconductor \\
\hline nanocrystals & synthesis \\
\hline multidisciplinary & sciences \\
\hline multilayer & films \\
\hline multilayers & magnetic \\
\hline multiline & positive
\end{tabular}




\begin{tabular}{ll}
\hline multiple & steps \\
\hline multiwalled & carbon \\
\hline multiwalled & nanotubes
\end{tabular}

Table 2. Examples of collocates.

d) Acronym finder, Word search, Crossword

The linguistic features examined so far (word lists, key word lists, collocates) offer suggestions for other activities:

Activity 1: Find out what a set of acronyms (used in the corpus) stand for:

- $\quad$ AFM - Atomic Force Microscope

- CNT - Carbon nanotube

- DWNT - Double-walled carbon nanotubes

- $\quad$ EBDW - Electron-Beam Direct-Write Lithography

- $\quad$ MWNT - Multi-walled nanotubes

- $\quad$ NEMS - Nanoelectromechanical systems

- $\quad$ P-SWNT - Polymerized single-walled nanotubes

- $\quad$ RIE - Reactive Ion Etching

- $\quad$ SEM - Scanning Electron Microscope

- $\quad$ SiNW - Silicon Nanowire

- $\quad$ SWNT - Single-walled nanotubes

- XRD - X-ray Diffraction

It should be noted that hundreds of acronyms are found in the corpus, being the ones above just a few selected examples.

Activity 2: Word Search for terms obtained as significant in the discipline (all of them with the prefix 'nano-'):

$\begin{array}{ll}\text { nanoimprint } & \text { nanodevice } \\ \text { nanoscopic } & \text { nanopore } \\ \text { nanochannel } & \text { nanostructure } \\ \text { nanoparticle } & \text { nanoelectronics } \\ \text { nanosized } & \text { nanorobotics } \\ \text { nanocomposite } & \text { nanotube } \\ \text { nanopillar } & \text { nanorod } \\ \text { nanosphere } & \text { nanowire } \\ \text { nanoscience } & \text { nanofiltration }\end{array}$

Activity 3: Provide the term for a given definition (creating a crossword): 


\begin{tabular}{|l|l|}
\hline Across: & Down: \\
1.Nanobiotechnology & 1. Nanolithography \\
3. Nanofabrication & 2. Nanofluidics \\
5. Nano-optics & 4. Nanocomputer \\
7. Micrometre & 6. Nanometre \\
8. Nanoscale & 9. Nano \\
10. Nanocrystal & \\
11. Nanofibres & \\
\hline
\end{tabular}

\section{Across:}

1. Applies the tools and processes of nano/microfabrication to build devices for studying biosystems.

3. Design and manufacture of devices with dimensions measured in nanometres.

5. Interaction of light and matter on the nanoscale.

7. A unit of measure equivalent to one-millionth of a metre

8. Between 0.1-100nm.

10. Molecular-sized solids formed with a repeating, 3D pattern of atoms or molecules with an equal distance between each part.

11. Hollow and solid carbon fibres with lengths on the order of a few microns and widths varying from tens of nanometres to around $200 \mathrm{~nm}$.

\section{Down:}

1. The art and science of etching, writing, or printing at the microscopic level, where the dimensions of characters are on the order of nanometers. This includes various methods of modifying semiconductor chips at the atomic level for the purpose of fabricating integrated circuits (ICs).

2. Controlling nanoscale amounts of fluids.

4. A computer made from components (mechanical, electronic, or otherwise) built at the nanometre scale.

6. One billionth of a metre. $10-9 \mathrm{~m}$, or a millionth of a millimetre.

9. A prefix meaning one billionth (1/1000000 000).

10.

\section{e) Word combinations: Lexico-grammatical patterns}

In previous stages, we have seen how the terms obtained as significantly relevant words in a corpus can be used in our EAP/ESP courses. Similarly, lexical co-ocurrences can be explained to learn about combinations between content words and, consequently, explore more complex concepts. The generation of concordance lines together with the extraction of repeated strings of words ( 3 to 8 words) will throw light on the behaviour of certain patterns of language ( 'word clusters' 'collocational frameworks'). They constitute a valuable resource to teach students important facts not only about terminology but also about lexis and grammar. In other words, the methodology proposed offers the teacher numerous possibilities to choose and retrieve from examples stored in the corpus. One of them is the most recurrent 
string:'preposition + the $+x+$ of $+y$ ' (this can be narrowed to particular structures with a specific preposition). Alternative possibilities include the practice of structures such as 'modals+passive', 'because of', 'due to the', etc. The examples below containing these strings could be turned into gap-fill exercises (by providing students with longer sentences/context):

\section{'At the * of'}

- $\quad$ it is necessary to look at the magnitude of the AC conductivity

- the current at the top of the paper is detected by the AFM

- $\quad$ the sample prepared at the $\mathbf{p H}$ of 13 exhibited the smallest size

- $\quad$ is highly localized at the tips of the nanoparticles

- $\quad$ electrical connections at the base of the NWs

\section{'It can be'}

- $\quad$ Thus, it can be concluded that the colorimetric signalling

- It can be anticipated that these color variations are related to

- $\quad$ In Fig. 8 it can be observed that flux permeates tended to

- $\quad$ it can be said that the decrease in nitrate rejection

\section{'X was used to'}

- $\quad$ spectroscopy was used to study the sily lation

- TEM was used to determine the size of

- A data acquisition system was used to monitor the permeate flow

- flow meter was used to regulate the trans membrane pressure

- $\quad$ An IR spectrum was used to analyse the structure of

\section{'In order to'}

- $\quad$ minimum effort in order to obtain tuned sensing systems

- $\quad$ has been normalized in order to better appreciate

- In order to follow the effect of the annealing process

- in order to remove the organic material

- In order to quantify the colour modulation

\section{'As a function of'}

- $\quad$ as a function of the particle percolation

- $\quad$ are interpreted as a function of the degree of percolation

- $\quad$ structures were grown as a function of beam energy

We could even show our students how language is built using preconstructed blocks or structures and how very often longer strings are formed by several chunks of language. In other words, one cluster becomes part of a longer pattern. 
- $\quad$ a function of the mwcnt concentration can be seen in figure 1(a)

- $\quad$ as a function of volume fraction can be seen in figure 1(b)

- the formation of cobalt silicates can also be evidenced by

\section{f) Reading an academic article/extract}

Depending on our students' linguistic competence, our last activity could involve reading a whole article or an extract and whose main objective would be identifying the different linguistic features referred to in the sections above. Assigning different texts to different students and their oral subsequent presentation of the text can promote the comparison and contrast of the typical structure of academic articles. Additionally, they can analyse and compare the use of certain terms and patterns across the different sections.

\begin{tabular}{|l|l|}
\hline 1. Introduction & Abstract \\
2. Experimental & 1. Introduction \\
3. Results and discussion & 2. Experimental \\
3.1. Photoluminescence & 2.1.Preparation of the silica supports \\
3.2. Raman spectra & 2.2.Synthesis of cobalt nanoparticles \\
4. Concluding remarks & 2.3.Preparation of Co/SiO2 catalysts \\
Acknowledgements & 2.4. Characterization techniques \\
References & 3. Results and discussion \\
& 4. Conclusions \\
& Acknowledgements \\
& References \\
\hline
\end{tabular}

For the more purely academic part of our agenda in setting out the basic elements of what we are calling English for Academic and Professional Purposes (EAPP), we have described a methodology using corpus-driven data to produce teaching materials that are linguistically as well as pedagogically rich. The different stages in the process can be carried out easily and quickly thanks to readily available computational tools. This means that there is no excuse for the teacher not making an ad hoc corpus and producing authentic materials based on real language evidence. Furthermore, as non-subject experts, language teachers using corpus linguistic techniques can acquire sufficient knowledge of the subject matter so as not to be at a disadvantage in the classroom with regards to the knowledge students bring from their specialist subjects. As new research areas emerge, we face the challenge of exploring emerging patterns of discourse through text analysis, which opens up new ways of designing our classroom materials. The learning process will be enhanced by the use of real examples of language use in academic and technical environments. The process is summarised in the following figure: 


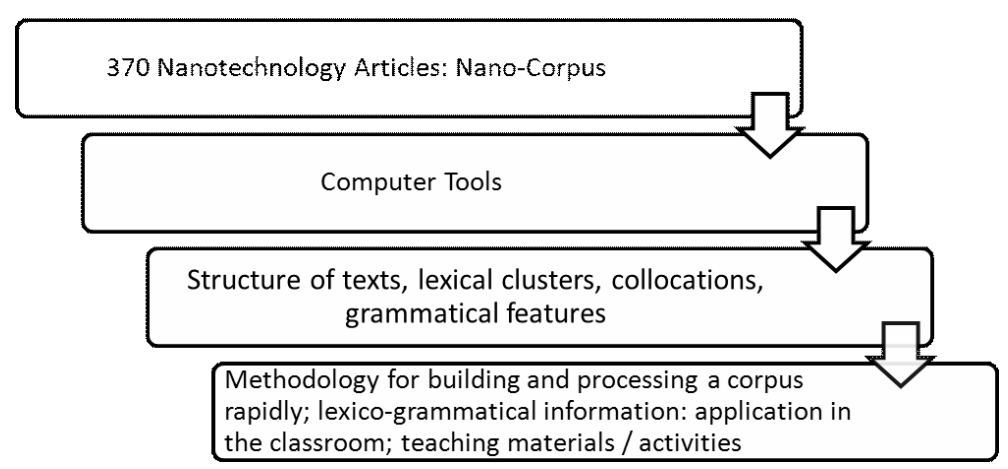

Figure 4. From corpus to EAPP teaching materials.

\section{Professional English and Interpersonal Skills}

So far, we have written about Academic English where the focus is on subject content and language skills. However, with Professional English, it is less bookish, less research-oriented and more work-oriented with hands on instruction needed; the guiding of students to acquire generic skills, which include the following competences:

- preparing oral presentations, learning to perform in meetings and negotiations,

designing innovations, completing projects, writing documents, preparing a business trip.

The teacher may want their students to create a professional portfolio of their work. These skills can be broken down into more specific communication and interpersonal skills:

- $\quad$ can communicate effectively in a variety of formal contexts;

- can participate actively in small group discussions;

- $\quad$ can present ideas clearly to an audience using current technological resources

- $\quad$ can negotiate effectively;

- can conduct interviews and surveys;

- can listen and take notes during meetings and presentations;

- $\quad$ can communicate effectively on the telephone as well as with video conferencing technology;

can analyse, synthesise and evaluate ideas;

- $\quad$ can edit texts for clarity and correctness;

- $\quad$ can work to agreed timetables, manage workloads, and meet deadlines;

- can apply variety of strategies including diplomacy and compromise to solve roblems;

- $\quad$ can speak English in an accent that is understood by a majority of English speakers;

- $\quad$ can give a formal presentation;

- $\quad$ can learn to receive and give criticism.

In what follows, we illustrate some examples of activities that are typical of English for Professional Purposes. The first group of activities are aimed at Business Management 
students while the second group are aimed at Engineering students.

\section{Activities for Business Management students}

1. Create your own company

Students are given a template that has been adapted from an original template designed by Barclays Bank for asking for bank loans to set up a business. This template consists of different aspects of a business such as the product or service to be offered; costs (and expenses) and the income that is to be generated by the business; marketing strategy; staff to be employed. Students, in pairs, fill in the template so as to start thinking about the company they are going to create and bring the completed template to tutorials to explain their business plan to their teacher. Once they have achieved this, they transfer the information from the template onto a PowerPoint presentation. Students give a 15 minute presentation of their company.

2. Mini-Lectures on Business Topics and Blogs

Students are given a brief talk of about ten minutes maximum on some aspect of Business Management. Among the topics, we lecture about are the following: Market Research, Human Resources Management, Business Organisation etc. After they have listened to the talk, they produce a 150 word summary and post the summary on a blog that they have maintained especially for their Business English classes.

\section{Oral Presentation}

Students prepare 15 minute oral presentations on a topic from one of their other degree course subjects. This adds an element of horizontal coordination with the other subjects students are studying and makes their English classes relevant to these other subjects.

\section{Activities for Engineering students}

\section{Webquest. Visiting a Company}

Students prepare a business trip (hotels, planes, business schedule etc.) to a company of their specialist subject. Mechanical Engineers visit companies such as Honda, Mercedes BMW. Industrial Design students visit companies such as IKEA. They prepare an oral presentation of their visit to the company in Japan, Germany or wherever, telling the class what they will do on each day of the visit. This activity is assessed both by the teacher and by the students (peer assessment).

2. Introducing my discipline and explanation of future jobs

Students from different engineering degrees (Mechanical, Chemical, Electrical, and Electronic Engineering) explain to each other (in groups) the nature of their discipline and what future jobs they will be capable of doing. This type of activity involves reflecting on their present academic environment and their future perspectives and interests. Oral presentations to the rest of the class will make them learn from other class mates about the different 
disciplines.

3. Invent their own wearable device

This activity is directly related to previous work realised in a learning module devoted to the topic of computers. In earlier stages, students have been given exercises and activities to practise different communicative skills related to the field of computers in general and their most relevant features. At the end of the unit, they carry out a more specific activity which involves visiting a web site where examples of already existing wearable devices are shown (computers that form part of their clothes or are worn like watches). Then, they form groups and invent their own wearable device. This activity, as one can imagine, is aimed at promoting students' inventiveness and imagination. Furthermore, by following the guidelines given on product presentation (shape, size, materials used, price, similar products on the market), our engineering students are making active use of their domain knowledge, that is, what they have been learning in their core subjects.

4. Invent a commercial product (brand name \& logo)

Again, this activity is intended to promote communicative activities tightly related to their professional settings. This simple exercise is one of the tasks in a learning module whose topic is the world of businesses (industrial sectors, company organisation, brands and brand names, logos, etc.). Students are given background information on the definition of brands, how brand names are chosen and their importance for the success of a company. Examples are given on the origin of well-known brand names and their logos. Then, they are asked to invent a brand name and design a logo for a product. This activity will be presented orally and their "final product" will also be posted in their blogs (the image of the logo, an explanation for the brand name).

\section{Conclusion: What does this mean for teachers of EAPP?}

This paper has set out an agenda for English for Academic and Professional Purposes at tertiary level in Spain. To be able to carry out the kind of teaching outlined in this paper, specific skills would need to be acquired by a teacher of EAPP. In line with what we have written above, the list below reflects some (but not all) of the key skills to be acquired:

- to be able to carry out an analysis of the overall needs of a group of student participants for a programme of English for Academic and Professional Purposes;

- to be able to conduct an analysis of the English required in a given specific domain of use through corpus linguistic techniques and text analysis;

- to be able to teach students to take a proactive role in working and developing professional skills and promote positive interpersonal relationships with others;

- to be able to help students reflect on their own and others practice with a view to professional development;

- to be able to design, teach and evaluate a programme of study in English for Academic and Professional Purposes; 
- demonstrate a comprehensive understanding of techniques applicable to research or advanced scholarship within the field of English for Academic and Professional Purposes.

Within this agenda, we have described a project where emphasis is placed on personalized learning and continuous evaluation. To this end, we have carried out diagnostic assessment on over 200 first year engineering and business management students at the beginning of this academic year. Now we are setting up personalized learning programs for weaker students to enhance their language skills.

We have also shown the practical implications and application of EAPP in the context of engineering and business and how both Academic and Professional language skills are crucial in university language teaching of English.

It is important to recognize that, first and foremost, EAPP teachers should be language experts. The language activities and the language analysis outlined in this paper show that rigorous quantitative and qualitative analysis of what is really needed in an academic and professional context is not only methodologically speaking a must, but also essential for teachers to check that students are being taught the language skills that are to be learnt for success in the workplace and professional settings. We can't afford to have teachers who don't know what students need to learn.

\section{References}

Alcaraz, Enrique (2000): El inglés profesional y académico. Madrid: Alianza Editorial.

Alderson, J. Charles, \& Wall, Diane (1993): “Does washback exist?". Applied Linguistics 14: 115-129.

Brown, James Dean (1999): "The roles and responsibilities of assessment in foreign language education". JLTA Journal 2: 1-21.

Gledhill, Chris (2000): "The discourse function of collocation in research article introductions". Journal of English for Specific Purposes 19: 115-135.

Manitoba Education, Citizenship, and Youth. (2006): "Rethinking Assessment with Purpose in Mind: assessment for learning, assessment as learning, assessment of learning”, Winnipeg, Manitoba, Canada: MECY.

[http://www.edu.gov.mb.ca/k12/assess/wncp/rethinking_assess_mb.pdf].

Martínez, Iliana A., Beck, Silvia C. \& Panza, Carolina B. (2009): “Academic vocabulary in agriculture research articles: A corpus-based study”. Journal of English for Specific Purposes 28: 183-198.

Scott, Mike (2004): WordSmith Tools version 4. Oxford: Oxford University Press.

Scott, Mike \& Tribble, Chris (2006): Textual patterns: Keyword and corpus analysis in language education. Amsterdam: Benjamins.

Sinclair, John (1991): Corpus, Concordance, Collocation. Oxford: Oxford University Press.

Ward, Jeremy (2007): “Collocation and technicality in EAP engineering”. Journal of English for Specific Purposes 6: 18-35. 